\title{
OBIEKTY KRENOLOGICZNE W DOLNEJ CZĘŚCI DORZECZA WISŁY (PO ZLEWNIĘ DRWĘCY)
}

\author{
ADAM CHOIŃSKI, MARIUSZ PTAK \\ Uniwersytet im. A. Mickiewicza w Poznaniu, \\ Zakład Hydrologii i Gospodarki Wodnej, \\ ul. B. Krygowskiego 10, 61-680 Poznań
}

\begin{abstract}
On the basis of hydrographic maps in the scale 1:50,000, an inventory of crenological objects in the lower part of the Vistula basin up to the Drwęca river basin in the south was made. The total number of these objects in the analyzed area is 308 , with the highest number of solid sources -161 , followed by leakages -125 and periodic sources -17 . The total efficiency of all outflows is very low, as it was estimated at $0.075 \mathrm{~m}^{3} \cdot \mathrm{s}^{-1}$. The most efficient source reaches only $1.0 \mathrm{dm}^{3} \cdot \mathrm{s}^{-1}$, and only a few $0.7 \mathrm{dm}^{3} \cdot \mathrm{s}^{-1}$.
\end{abstract}

Keywords: crenological facilities, lower part of the Vistula river basin, hydrographic map

\section{WSTĘP}

Hydrograficzne kartowanie terenowe obszaru Polski było prowadzone od początku lat 80 . XX w. W jego wyniku opublikowano około 700 arkuszy mapy hydrograficznej w skali $1: 50$ 000. Od 1998 r. mapy te wykonywane są w układzie 1992 (Sikorska 2004). Zawierają one ogromny ładunek danych hydrograficznych i hydrologicznych po raz pierwszy dla tak dużego obszaru. Umożliwia to tym samym wykonanie różnorodnych analiz tematycznych. Jednym z przykładów może być inwentaryzacja obiektów krenologicznych i to właśnie stanowi cel poniższej pracy. Jako obszar analizy wytypowano dolną część dorzecza Wisły po dorzecze Drwęcy, co było podyktowane dostępnością opracowanych map dla tej części dorzecza Wisły (ryc. 1).

Należy zaznaczyć, że strefa obszaru Polski nizinnej jest bardzo słabo zbadana pod względem stosunków krenologicznych, czego dowodem jest mała liczba opracowań. Spośród nielicznych należy wymienić prace: Łagodzińskiej i Tomalaka (1965), Choińskiego (1995), Małeckiej i Małeckiego (1998), Baścik, PociaskKarteczki (2002), Moniewskiego (2004), Cieślińskiego i Leśniowskiego (2013), a także wzmianki wielu autorów na temat analizy o charakterze lokalnym lub regionalnym zawarte w pracy Źródta Polski. Wybrane problemy krenologiczne (Jokiel i in. 2007). Oprócz wymienionych prac są również opracowania Tomaszewski (1977), Kryza (1986) z dorzecza Odry dotyczące strefy gór, np. Karkonoszy.

Na podstawie analizy map hydrograficznych powstały dwie prace o charakterze syntez. Pierwsza dotyczy obiektów krenologicznych dorzecza Odry (Cho- 


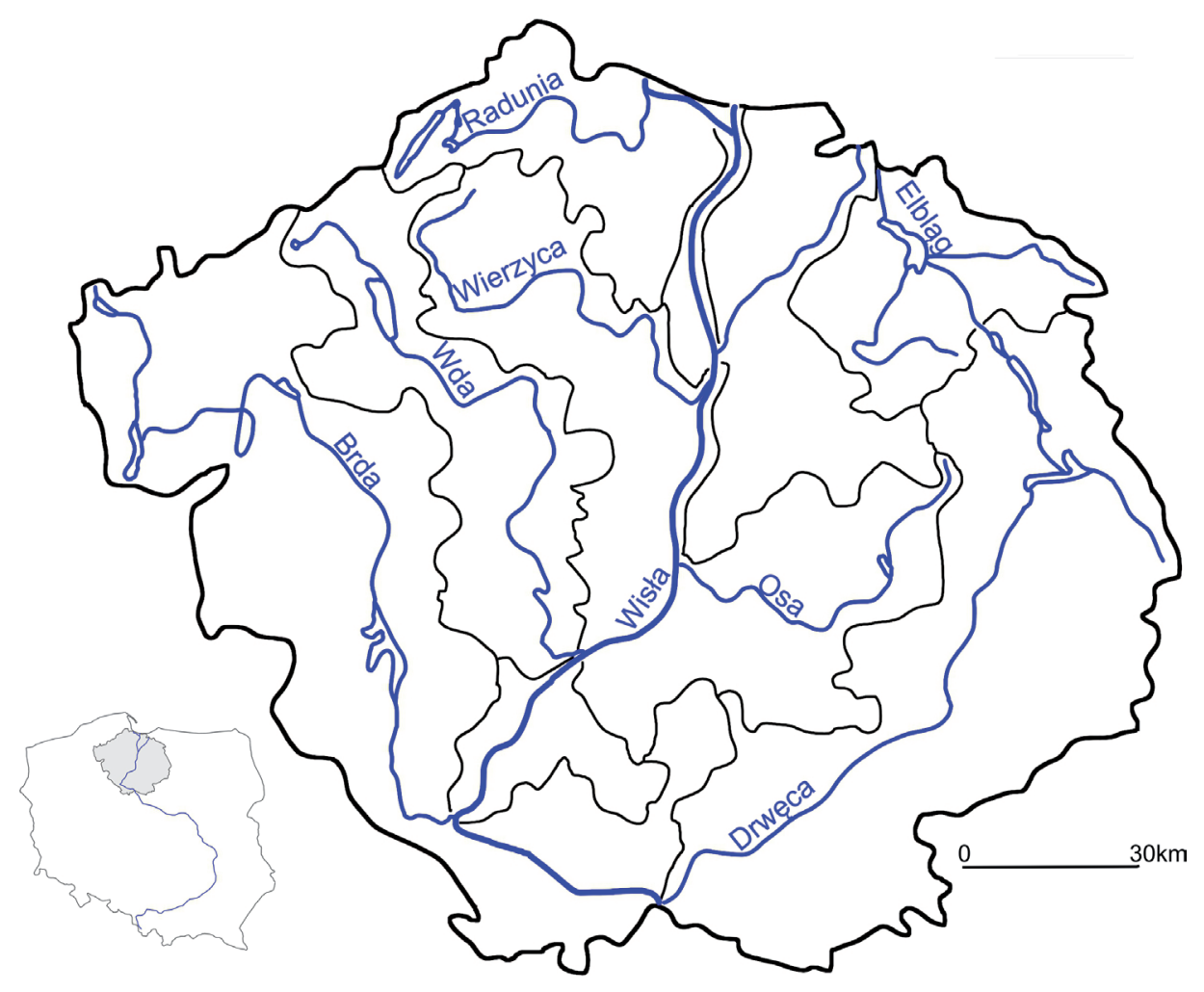

Ryc. 1. Lokalizacja obszaru badań

Fig. 1. Location of the research area

iński, Ptak 2009), druga zaś zlewni Przymorza i Zalewu Szczecińskiego (Choiński 2009). Pierwsza z prac obejmuje swym zasięgiem obszar $106056,5 \mathrm{~km}^{2}$ (33,9\% powierzchni Polski), na którym zlokalizowano łącznie 2611 obiektów krenologicznych, a druga odpowiednio $18498,4 \mathrm{~km}^{2}$ (5,93\% powierzchni Polski), gdzie zlokalizowano 336 obiektów krenologicznych. Łączna wydajność wszystkich wypływów jest niewielka i wynosi odpowiednio: $1,645 \mathrm{~m}^{3} \cdot \mathrm{s}^{-1}$ oraz $0,1235 \mathrm{~m}^{3} \cdot \mathrm{s}^{-1}$.

Choć można mieć pewne zastrzeżenia do dokładności pomiarów terenowych, przedstawionych na mapach hydrograficznych w skali $1: 50000$, to jednak w odniesieniu do obszarów o dużej powierzchni jest to jedyne źródło informacji. Przykładami uzyskania wyników różniących się pod względem i liczby, i wydajności obiektów krenologicznych w stosunku do wyników wspomnianego kartowania mogą być prace Puka (2008) i Szczucińskiej (2008). Pierwsza z nich dotyczy okolic Sierakowa, druga zaś Rynny Gryżyńsko-Grabińskiej. Różnice w powyższym przypadku wynikają po pierwsze z kilkuletniego okresu pomiarowego tych samych obiektów, a po drugie z bardzo szczegółowego 
kartowania terenowego, co jest możliwe w przypadku obszaru o niewielkiej powierzchni.

\section{MATERIAŁY I METODY}

Niniejsze opracowanie obejmuje 104 arkusze map hydrograficznych w skali $1: 50000$ (ryc. 2).

W zasięg analizowanego obszaru całkowicie wchodzi 61. arkuszy, pozostałe zaś tylko częściowo. Wynika to z ich lokalizacji na obrzeżu obszaru, czyli z przebiegu działów wodnych. Powierzchnia badanej części dorzecza Wisły (w skład którego wchodzi 10 dorzeczy) wynosi $21394,7 \mathrm{~km}^{2}$, co stanowi 6,84\% powierzchni Polski. Dane uzyskane z map hydrograficznych oparte są na badaniach terenowych prowadzonych głównie w latach 2000-2015, przy czym dwa arkusze wydano przed rokiem 2005, 51 arkuszy w latach 2005-2010 oraz 51 arkuszy po roku 2010. Zdecydowaną większość pomiarów wykonywano w miesiącach letnich, zatem określone wydajności odnoszą się do tego okresu i w zależności od regionu mogą być różne w porównaniu z wydajnością średnią roczną. Wydzielenia obiektów krenologicznych przyjęto zgodnie z zasadami przyjętymi na mapie hydrograficznej, z zastosowaniem stosownej instrukcji. Przy ustalaniu wydajności przyjęto następujące założenia: źródła stałe i młaki o wydajności poniżej $0,5 \mathrm{dm}^{3} \cdot \mathrm{s}^{-1}$, mające wydajność $0,25 \mathrm{dm}^{3} \cdot \mathrm{s}^{-1}$, dla młak o wydatku większym niż $0,5 \mathrm{dm}^{3} \cdot \mathrm{s}^{-1}$ ustalono wydajność $0,5 \mathrm{dm}^{3} \cdot \mathrm{s}^{-1}$, zespołom źródeł stałych przyporządkowano $1 \mathrm{dm}^{3} \cdot \mathrm{s}^{-1}$, wyciekom $0,1 \mathrm{dm}^{3} \cdot \mathrm{s}^{-1}$, źródłom o danym zakresie wydajności wartość średnią, źródłom okresowym zaś $0 \mathrm{dm}^{3} \cdot \mathrm{s}^{-1}$.

\section{WYNIKI I DYSKUSJA}

Z analizy map hydrograficznych wynika, że na 25 arkuszach (spośród 104) zlokalizowano 308 obiektów krenologicznych. Wśród nich zdecydowanie najwięcej jest źródeł stałych - 161 (52,3\%), następnie wycieków - 125 (40,6\%), źródeł okresowych - 17 (5,5\%), młak - 3 (1,0\%) oraz źródeł mineralnych - 2 $(0,6 \%)$. Gęstość obiektów krenologicznych na omawianym obszarze przedstawiono za pomocą kartogramu, wydzielając sześć przedziałów klasowych (ryc. 3).

Uzyskany rozkład jest bardzo zróżnicowany. Najwięcej obiektów udokumentowano w obrębie następujących arkuszy: Nowe (66), Gniew (36), Brusy (33) oraz Górzno (29). Na analizowanym obszarze dorzecza Wisły jeden obiekt krenologiczny przypada średnio zaledwie na $69 \mathrm{~km}^{2}$. Interesujący jest problem wydajności obiektów krenologicznych. Został on przedstawiony o obrębie poszczególnych arkuszy (ryc. 4) oraz analizowanych zlewni (tab. 1). Wybrane przykłady wypływu wód podziemnych przedstawiono na fotografii 1 . 


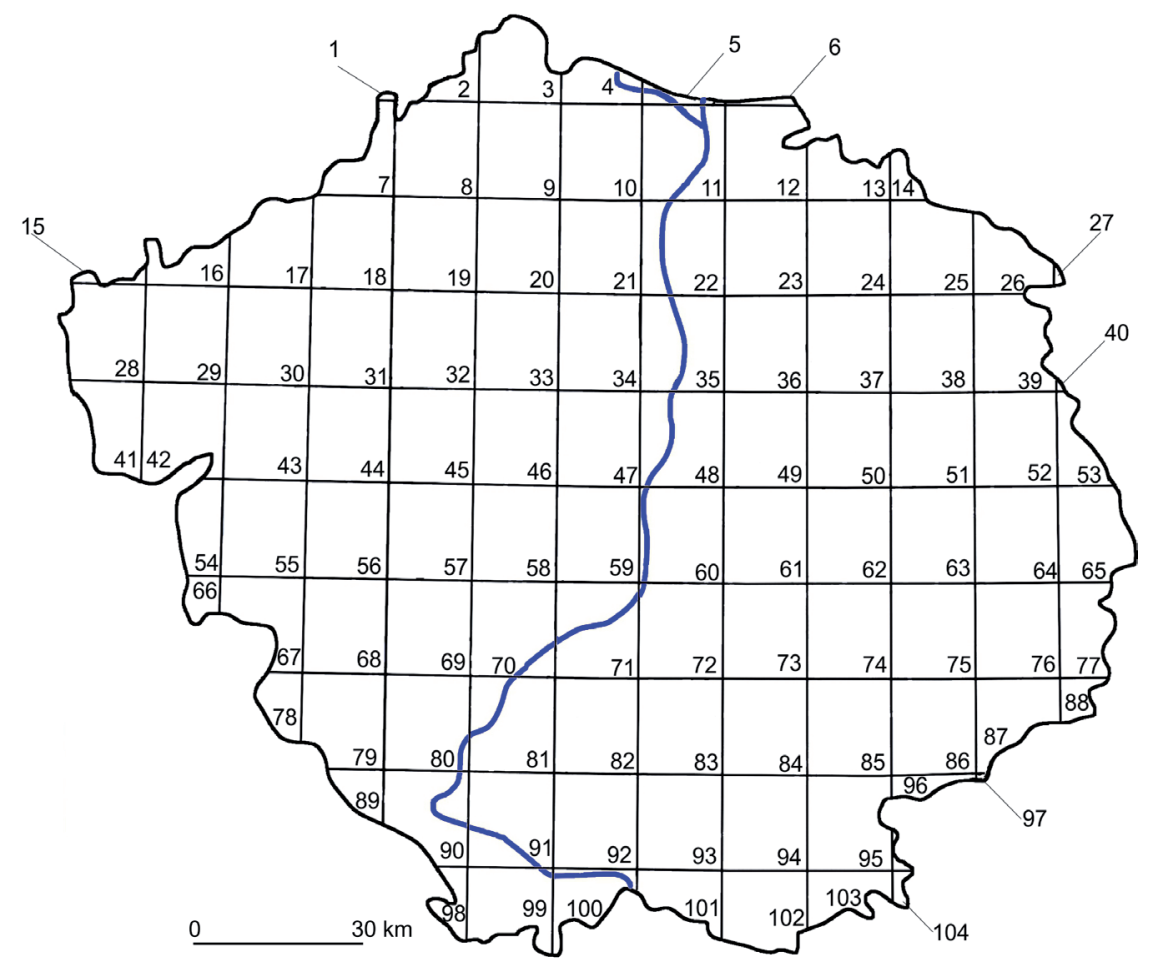

Ryc. 2. Podział obszaru badań na arkusze map hydrograficznych w skali $1: 50000$

Fig. 2. Division of the survey area into sheets of hydrographic maps in the scale $1: 50000$

1. Sierakowice, 2. Kartuzy Płn., 3. Gdańsk-Osowa, 4. Gdańsk, 5. Gdańsk-Sobieszowo, 6. Kąty Rybackie, 7. Bytów-Wsch., 8. Stężyca, 9. Kartuzy Płd., 10. Kolbudy Górne Przywidz, 11. Pruszcz Gdański, 12. Suchy Dąb Ostaszewo, 13. Nowy Dwór Gdański, 14. Elbląg Płn., 15. Kramarzyny, 16. Tuchomie, 17. Studzienice, 18. Kościerzyna, 19. Nowa Karczma, 20. Skarszewy, 21. Sobowidz, 22. Tczew, 23. Malbork, 24. Elbląg Płd., 25. Pasłęk, 26. Godkowo, 27. Orneta, 28. Kaczała, 29. Lipnica, 30. Brusy, 31. Karsin, 32. Czarna Woda, 33. Zblewo, 34. Starogard Gdański, 35. Gniew, 36. Sztum, 37. Dzierzgoń, 38. Zalewo, 39. Morąg, 40. Świątki, 41. Rzecznica, 42. Człuchów Płn., 43. Chojnice, 44. Czersk, 45. Śliwice, 46. Osiek, 47. Skórcz, 48. Kwidzyn, 49. Prabuty, 50. Susz, 51. Jerzwałd, 52. Ostróda, 53. Łukta, 54. Człuchów Płd., 55. Kamień Krajeński, 56. Tuchola, 57. Cekcyn, 65. Gierzwałd, 66. Więcbork, 67. Sępólno Krajeńskie, 68. Gostycyn, 69. Bukowiec Lubiewo, 70. Świecie, 71. Grudziądz-Mniszek, 72. Grudziądz, 73. Jabłonowo Pomorskie, 74. Zbiczno, 75. Nowe Miasto Lubawskie, 76. Rybno, 77. Dąbrówno, 78. Mrocza 79. Koronowo, 80. Pruszcz, 81. Unisław, 82. Chełmża, 83. Wąbrzeźno, 84. Książki, 85. Brodnica, 86. Górzno, 87. Lidzbark, 88. Działdowo, 89. Bydgoszcz Zach., 90. Bydgoszcz Wsch., 91. Zławieś Wielka Lubianka, 92. Toruń, 93. Kowalewo Pomorskie, 94. Golub-Dobrzyń, 95. Rypin, 96. Skrwino, 97. Żuromin, 98. Złotniki Kujawskie, 99. Gniewkowo, 100. Aleksandrów Kujawski, 101. Ciechocinek, 102. Lipno, 103. Skępe, 104. Sierp 


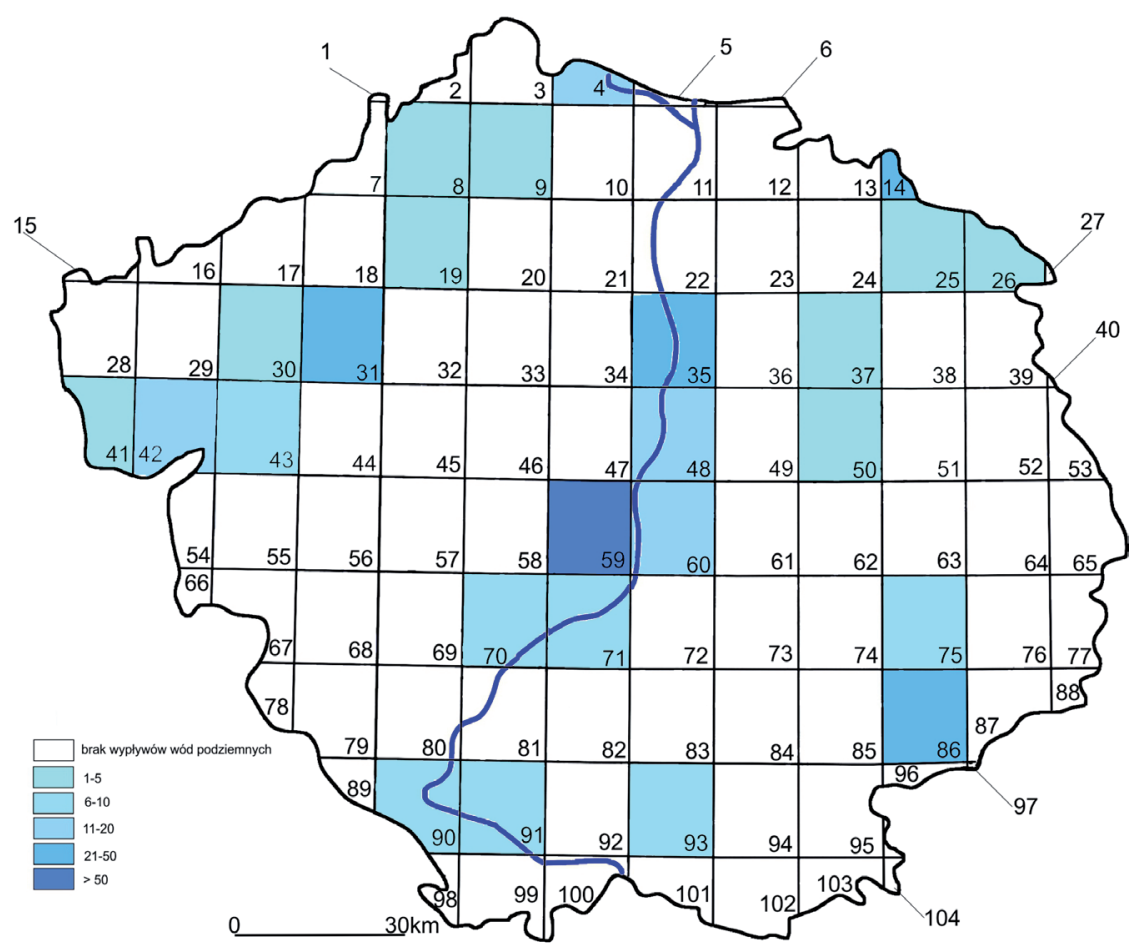

Ryc. 3. Liczba wypływów wód podziemnych w dolnej części dorzecza Wisły w obrębie poszczególnych arkuszy

Fig. 3. Number of groundwater outflows in the lower part of the Vistula basin within the individual sheets

Tabela 1. Liczba i wydajność wypływów wód podziemnych analizowanego obszaru według podziału hydrograficznego

Table 1. Number and efficiency of groundwater outflows of the analysed area by hydrographic division

\begin{tabular}{lcc}
\hline \multicolumn{1}{c}{ Zlewnia } & Liczba wypływów wód podziemnych & Łączna wydajność $\left[\mathrm{dm}^{3} \cdot \mathrm{s}^{-1}\right]$ \\
\hline Elbląg & 32 & 7,2 \\
Drwęca & 46 & 9,65 \\
Brda & 60 & 31,4 \\
Wierzyca & 14 & 5,7 \\
Osa & 9 & 3,95 \\
Nogat & 4 & 2,5 \\
Radunia & 2 & 1,25 \\
Martwa Wisła & 7 & 2,15 \\
Wda & 8 & 10,85 \\
Wisła & 3 & 0,75 \\
\hline
\end{tabular}




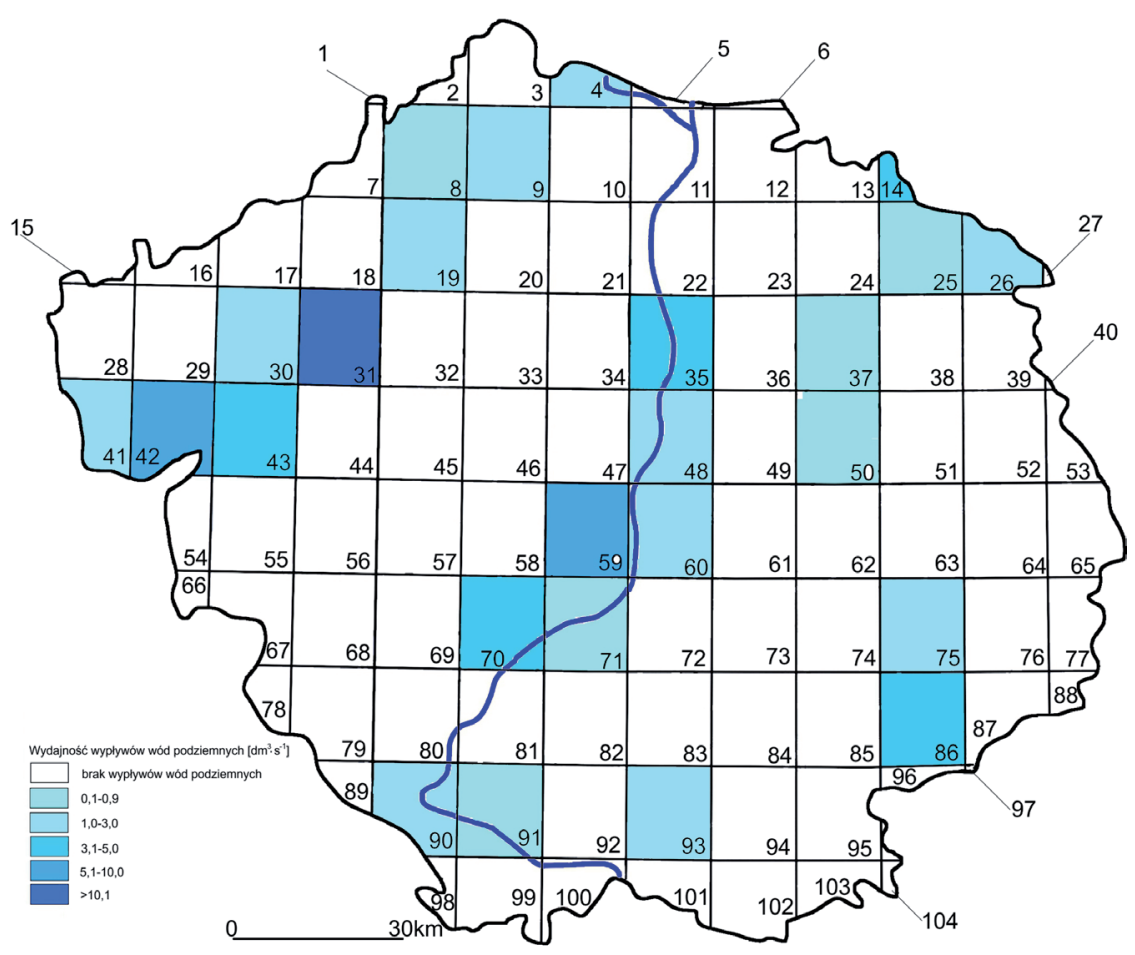

Ryc. 4. Sumaryczna wydajność wypływów wód podziemnych w dolnej części dorzecza Wisły w obrębie poszczególnych arkuszy

Fig. 4. Summary efficiency of groundwater outflows in the lower part of the Vistula basin within the individual sheets

Największe sumaryczne wydajności zanotowano w obrębie następujących arkuszy: Brusy $16,4 \mathrm{dm}^{3} \cdot \mathrm{s}^{-1}$, Elbląg Płn. $\left(4,75 \mathrm{dm}^{3} \cdot \mathrm{s}^{-1}\right)$ oraz Chojnice $(4,6$ $\mathrm{dm}^{3} \cdot \mathrm{s}^{-1}$ ), a największe łączne wydajności występują w zlewniach: Brdy 31,4 $\mathrm{dm}^{3} \cdot \mathrm{s}^{-1}$ oraz Drwęcy $\left(7,75 \mathrm{dm}^{3} \cdot \mathrm{s}^{-1}\right)$. Całkowita wydajność wszystkich obiektów krenologicznych w granicach analizowanego obszaru jest wyjątkowo mała i została określona na $0,075 \mathrm{~m}^{3} \cdot \mathrm{s}^{-1}$.

\section{WNIOSKI}

Biorąc pod uwagę opracowania dotyczące Odry, zlewni przymorza i Zalewu Szczecińskiego oraz powyższe, można stwierdzić, iż zinwentaryzowano źródła na obszarze 145 949,6 km² (co stanowi 46,7\% Polski), w liczbie 3255. Ich łączna wydajność wynosi $1,8435 \mathrm{~m}^{3} \cdot \mathrm{s}^{-1}$. Powyższe opracowanie stanowi uzupełnienie wiedzy o występowaniu zjawisk krenologicznych na obszarze Polski. Mimo to niedobór informacji z tego zakresu jest ciągle znaczny i dotyczy głównie wschodniej części Polski. 

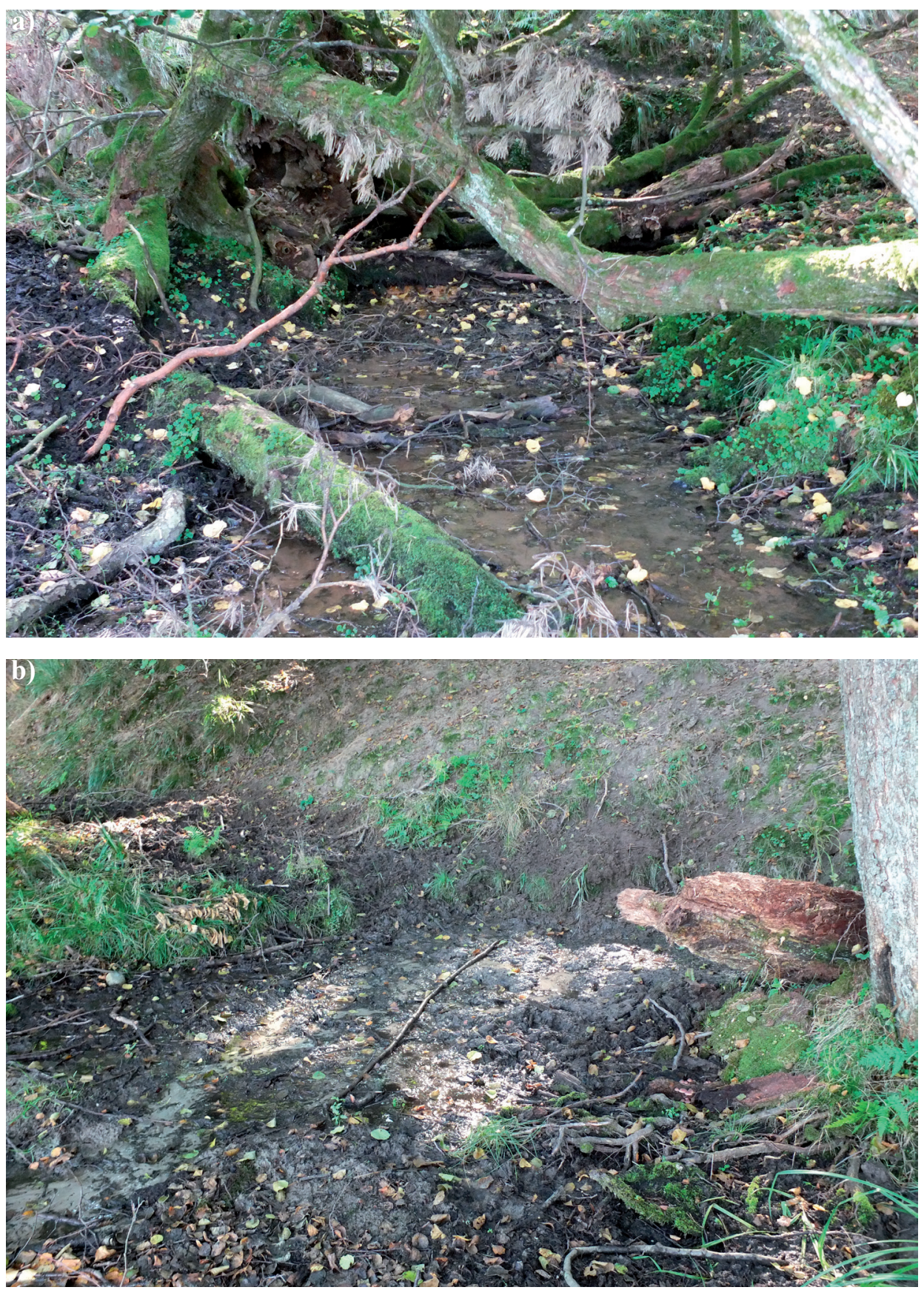

Fot. 1. Przykłady wypływów wód podziemnych, a-) okolice jeziora Główki, b) okolice jeziora Płęsno (fot. W. Błoniarz)

Phot. 1. Examples of groundwater outflows, a) surroundings of Lake Główka, b) surroundings of Lake Płęsno (phot. W. Błoniarz) 
Najprawdopodobniej, tak jak w przypadku jezior, występuje tendencja zaniku obiektów krenologicznych bądź zmniejszania ich wydajności, co sygnalizowała już w ubiegłym wieku Dynowska (1986). Zjawisko to może być następstwem np. obniżania się pierwszego poziomu wodonośnego w wyniku wielkopromiennych melioracji lub nadmiernej eksploatacji wód. Powyższa inwentaryzacja wydaje się celowa, gdyż może okazać się przydatną do określenia zmian w przyszłości. Ponadto jest realizowany postulat prof. Ireny Dynowskiej, która ponad 30 lat temu twierdziła: „Obszar Niżu, obejmujący $3 / 4$ terytorium Polski, jest pod względem stosunków krenologicznych najmniej zbadany" (Dynowska 1986).

\section{LITERATURA}

Baścik M., Pociask-Karteczka J., 2002: Źródła Wyżyny Śląsko-Krakowskiej i Wyżyny Małopolskiej o znacznych walorach przyrodniczych. Propozycje ochrony, [w:] T. Ciupa, E. Kupczyk, R. Suligowski (red.), Obieg wody w zmieniajacym się środowisku, Pr. Inst. Geogr. AŚ, 7, 23-39.

Choiński A., 1995: Źródła środkowej części Niziny Wielkopolskiej, Spr. Wydz. Mat.-Przyr., 109, Wyd. PTPN, Poznań, 42-48.

Choiński A., 2009: Obiekty krenologiczne w zlewni przymorza i Zalewu Szczecińskiego, [w:] R. Bogdanowicz, J. Fac-Beneda (red.), Zasoby i ochrona wód. Obieg wody i materii w zlewniach rzecznych, FRUG, Gdańsk, 353-360.

Choiński A., Ptak M., 2009: Obiekty krenologiczne dorzecza Odry, Przegl. Geogr., t. 81(3), 365372.

Cieśliński R., Leśniowski P., 2013: Wypływy wód podziemnych $w$ województwie pomorskim, Gosp. Wod., 8, 306-311.

Dynowska I., 1986: Regionalne zróżnicowanie źródet w Polsce, Fol. Geograph., 18, 5-30.

Jokiel P., Moniewski P., Ziułkiewicz M., 2007: Źródła Polski. Wybrane problemy krenologiczne, Wydz. Nauk Geogr. UŁ, Łódź, 352.

Kryza H., 1986: Zróżnicowanie przestrzenne odpływu podziemnego zlewni sudeckich na przykładzie zlewni Kamienicy (Masyw Śnieżnika), Pr. Nauk. Inst. Geotechn. PW, 49, Ser. Konferencyjna, 21, 101-106.

Łagodzińska J., Tomalak S., 1964: Źródła w dolinie Warty na odcinku od Śremu do Obornik Wlkp., Spraw. PZPN za III i IV kwartał 1964, Poznań, 307-310.

Małecka D., Małecki J., 1998: Warunki hydrogeologiczne i hydrochemiczne oraz określenie dziatań majacych na celu ochronę rezerwatu Niebieskie Źródła, Ofic. Wydawn. PW, Warszawa, $65-67$.

Moniewski P., 2004: Źródła okolic Łodzi, Łódzkie Tow. Nauk., Łódź, 140.

Puk K., 2008: Wyplywy wód podziemnych $i$ ich zmienność $w$ wybranych zlewniach dorzecza środkowej Warty, Inst. Geogr. Fiz. i Kształtowania Środ. Przyr., UAM, Poznań, 329 [maszynopis].

Sikorska K., 2004: Stan i perspektywy mapy hydrograficznej i sozologicznej Polski w skali 1 : 50 000, [w:] , Kartografia tematyczna w ksztattowaniu środowiska geograficznego”, XXX Ogólnopolska Konferencja Kartograficzna, Poznań 21-22.10.2004, Mat. Ogólnopolskich Konf. Kart., 25, UAM, Inst. Geogr. Fiz. i Kształtowania Środ. Przyr., PTG, Oddz. Kart., Poznań, $20-25$.

Szczucińska A.M., 2008: Wyplywy wód podziemnych w Rynnie Gryżyńsko-Grabińskiej, Inst. Geogr. Fiz. i Kształtowania Środ. Przyr., UAM, Poznań, 150 [maszynopis].

Tomaszewski J., 1977: Charakterystyka krenologiczna masywu krystalicznego na przyktadzie Karkonoszy, Act. Univ. Wratislaviensis, 358, Stud. Geogr., 28, 68. 